\title{
Assimilation surface and photosynthetic activity evaluation of winter wheat planting according to forecrops and mineral fertilizers
}

\author{
Aleksandr Gurin", Galina Ignatova, Elena Stepanova, Aleksey Tarakin and Natalya \\ Velkova
}

Orel State Agrarian University, 302040, Orel, Russian Federation

\begin{abstract}
The article shows the results of multi-year researches on the photosynthetic activity of winter wheat plantings according to forecrops and mineral fertilizers. The studies were performed in a two-factor experiment. Forecrops of winter wheat affected to the formation of the assimilation mechanism of plants. This influence can be seen in all phases of wheat growth. It was revealed that the best indicators were ensured by the planting of grain crops with seeding on green manure. For these variants, the leaf-area duration in the flowering phase was 42.6-49.7 thousand $\mathrm{m} 2$ / ha. The cultivation of bean cultures to grain was slightly lower in this indicator. The leaf area was 3.6-20.0\% smaller depending on the cropping. The use of bean cultures as green manure crops led to an increase in the photosynthetic potential to 2449.1-2671.8 thousand $\mathrm{m} 2$ /day / ha, which is $6.1-12.6 \%$ more than in the variants where bean cultures were grown to grain. The greatest photosynthetic potential was with the use of lupine to green manure. Application of mineral fertilizers also had a positive effect on the development of the assimilation mechanism. On complete fallow without mineral fertilizers, this indicator was 2325.7 thousand $\mathrm{m} 2 \times$ day / ha, and when additional fertilizers were applied at a dose of N54P52K52, the photosynthetic capacity increased by 70.5 thousand $\mathrm{m} 2 \times$ day/ha or by $30 \%$. Following the green manure crops, the yield of winter wheat slightly outperformed the crop in the variants where bean cultures were grown to grain, both without fertilization and on the background of fertilizers. The application of mineral fertilizers promoted a greater increase in the yield, in contrast to the forecrop. With the use of mineral fertilizers, the yield increased by $11-12 \%$ in similar variants.
\end{abstract}

\section{Introduction}

Among the significant agrotechnical measures for the cultivation of winter wheat, the selection of forecrops is also of great importance. Winter wheat is one of the most demanding plants for its forecrop $[1,2,3]$.

\footnotetext{
*Corresponding author: aeoos@mail.ru
} 
In the Central black earth economic region, the best forecrops are complete and green manure fallows $[4,5,6]$.

Field crops, especially bean used as green manures have a high fertilizer value. Green fertilizers increase the agrochemical properties of the soil. Under the influence of green manure, the acidity reduces, the amount of absorbed bases increases, but the most valuable thing is that with the green mass, up to $200 \mathrm{~kg}$ of nitrogen, up to $70 \mathrm{~kg}$ of phosphate and up to $170 \mathrm{~kg}$ of potassium is fed into the soil $[7,8,9]$.

Forecrops play an undeniable role in the formation of high productivity of winter wheat $[10,11]$. An essential part of the assimilation surface of agricultural crops, including winter wheat, down to the leaves, since they are mainly carried out photosynthesis. The study of the assimilation surface of the leaves is significant. The leaf-area duration of plants may vary in rather wide intervals, depending on the growing conditions, as well as during the growing season. It is known that the maximum absorption of photosynthetically active radiation is carried out when the area of the assimilation surface is about 40-50 thousand $\mathrm{m} 2$ / ha.

During the beginning of plant development, the assimilation surface of winter wheat crops is small. In the future, the growth rate of the leaf area grows and reaches a maximum by the time the linear growth stops. At the end of the growing season, the assimilation surface reduces due to the death of the lower leaves. It is crucial to provide the maximum growth of the leaf surface by the time of grain formation, which is the main guarantee of high yields. Consequently, the study of the formation dynamics of the leaf surface on winter wheat crops is significant.

To this end, the study of particular forecrops in the conditions of the gray forest soil of the Northern part of the Central black earth economic region is an urgent task.

\section{Materials and methods}

The research was carried out in a two-factor experiment, in the experimental production farm "Orlovskoye".

Variants of the experiment: Factor A: 1. Complete fallow -(control); 2. Peas to grain; 3. Peas to green manure; 4. Lupin to grain; 5. Lupin to green manure; 6 . Vetch + oats to grain; 7. Vetch + oats to green manure.

Factor B: 1. No application of mineral fertilizers; 2. $\mathrm{N}_{54} \mathrm{P}_{52} \mathrm{~K}_{52}$.

The experience is based on a three-fold repetition. The plot area is $120 \mathrm{~m}^{2}$. Objects of research: winter wheat-Moscow 39; peas-Temp; blue lupine-Orlovsky siderate; spring vetch - Nikolskaya; oats-Skakun. In complete fallow, $20 \mathrm{t} / \mathrm{ha}$ of cattle manure was brought. In the versions with the use of mineral fertilizers, a 10:26:26 - $2 \mathrm{c} /$ ha of diammophoska was brought in in the autumn, and $1 \mathrm{c} / \mathrm{ha}$ of ammonium nitrate was put in in the spring.

Green manure crops were mowed with grinding with a rotary mower KIR-1.5 in the budding-flowering phase, following the ploughing of the ground mass with a plow PN-4-35 to a depth of $20-25 \mathrm{~cm}$.

Phenological observations of the growth and development of plants were conducted according to the methodology of the state variety testing of agricultural crops. The dynamics of leaf surface formation, photosynthetic potential, and net photosynthetic productivity of winter rye were determined according to A. A. Nichiporovich [12].

\section{Results and discussion}


Studies conducted have revealed that the assimilation surface of winter wheat leaves in the initial growing season is negligible and ranges from 8.0 to 11.6 thousand $\mathrm{m} 2 /$ ha, depending on the variant.

Within the time of booting, the area of the leaf surface grows more than twice and amounted to $15.3-23.2$ thousand $\mathrm{m} 2 / \mathrm{ha}$, depending on the variants.

Maximum growth of the leaf surface is observed in the flowering phase. During this period, the assimilation surface of winter wheat crops was 39.7-54.8 thousand $\mathrm{m}^{2} / \mathrm{ha}$.

In the phase of milky-waxy ripeness, the leaf surface area was considerably decreased and amounted to 8.9-13.7 thousand $\mathrm{m}^{2}$ /ha according to the experimental variants.

Forecrops of winter wheat had a considerable influence on the formation of the assimilation mechanism of plants. This influence can be seen in all phases of wheat development.

The best indicators were found to be provided by the sowing of bean cultures with seeding on green manure. In these variants, the leaf surface area in the flowering phase was 42.6-49.7 thousand $\mathrm{m}^{2} /$ ha. The cultivation of bean cultures to grain was rather lower in this indicator. The leaf area here was 3.6-20.0\% smaller, depending on the crop.

Bean cultures to grain almost did not vary in this indicator from autumn fallow (control), 39.7-41.4 thousand $\mathrm{m}^{2} /$ ha in the variants with the planting of bean cultures to grain and 40.3 thousand $\mathrm{m}^{2} /$ ha in the control version.

Application of mineral fertilizers also had a positive effect on the assimilation mechanism formation. Notwithstanding the fact that bean cultures leave behind a sufficient amount of nutrients for subsequent crops, however, application of mineral fertilizers promoted the activation of winter wheat growth processes. So, in the control variant without mineral fertilizers application, the leaf surface area during the flowering period was 40.3 thousand $\mathrm{m}^{2} /$ ha for 4 years of research, which is $8.7 \%$ more than it was earlier. Assimilation surface increase of winter wheat leaves was seen in all similar variants.

The largest area of the leaf surface was noted after planting lupine to green manure with the application of mineral fertilizers at a dose of $\mathrm{N}_{54} \mathrm{P}_{52} \mathrm{~K} 52-54,8$ thousand $\mathrm{m}^{2} /$ ha, versus 49,7 thousand $\mathrm{m}^{2} /$ ha in a similar version, but without applying mineral fertilizers.

It is necessary to apply additional mineral fertilizers after bean forecrops to form the optimal area of the assimilation mechanism on winter wheat crops in the conditions of gray forest soil.

An essential indicator directly affecting the productivity of winter wheat is the photosynthetic potential. It is an index of changes in the size of the assimilation surface of the leaves and the duration of their contribution.

Photosynthetic potential is determined by many factors, and above all by the conditions affecting the intensity of plant growth processes.

The findings revealed that the photosynthetic potential was not the same in different phases of vegetative development (tabl. 1).

Table 1. Photosynthetic potential of winter wheat, depending on the forecrops and fertilizer application, thousand $\mathrm{m}^{2} \times$ day / ha (2016-2019)

\begin{tabular}{|l|c|c|c|c|c|}
\hline \multirow{2}{*}{ Variants } & \multicolumn{6}{|c|}{ Phenological phase } \\
\cline { 2 - 6 } & $\begin{array}{c}\text { seedlings } \\
\text { - autumn } \\
\text { tillering }\end{array}$ & $\begin{array}{c}\text { spring } \\
\text { tillering- } \\
\text { booting }\end{array}$ & $\begin{array}{c}\text { booting - } \\
\text { flowering }\end{array}$ & $\begin{array}{c}\text { flowering - } \\
\text { milky-wax } \\
\text { ripeness }\end{array}$ & $\begin{array}{c}\text { seedlings - } \\
\text { fully ripe }\end{array}$ \\
\hline \multicolumn{7}{|c|}{ without mineral fertilizers } & 913,6 & 2325,7 \\
\hline Complete fallow (control) & 309,7 & 343,1 & 759,3 & 898,4 & 2308,2 \\
\hline Peas to grain & 311,2 & 351,7 & 746,9 & 921,6 & 2449,1 \\
\hline Peas to green manure & 327,1 & 376,3 & 824,1 & 25 \\
\hline
\end{tabular}




\begin{tabular}{|l|c|c|c|c|c|}
\hline Lupin to grain & 328,9 & 354,9 & 778,4 & 909,7 & 2371,9 \\
\hline Lupin to green manure & 351,6 & 382,2 & 916,7 & 1021,3 & 2671,8 \\
\hline Vetch + oats to grain & 306,4 & 321,8 & 735,9 & 907,6 & 2271,7 \\
\hline Vetch + oats to green manure & 327,6 & 349,3 & 751,8 & 921,1 & 2349,8 \\
\hline \multicolumn{7}{|c|}{$\mathrm{N}_{54} \mathrm{P}_{52} \mathrm{~K}_{52}$} \\
\hline Complete fallow (control) & 313,4 & 361,2 & 787,9 & 936,7 & 2396,2 \\
\hline Peas to grain & 331,1 & 369,7 & 801,2 & 919,6 & 2421,6 \\
\hline Peas to green manure & 343,6 & 391,1 & 847,5 & 961,8 & 2544,0 \\
\hline Lupin to grain & 339,9 & 375,3 & 803,9 & 927,3 & 2446,4 \\
\hline Lupin to green manure & 389,4 & 403,1 & 882,7 & 1093,2 & 2767,5 \\
\hline Vetch + oats to grain & 359,1 & 364,8 & 789,1 & 928,5 & 2441,5 \\
\hline Vetch + oats to green manure & 337,6 & 360,4 & 786,9 & 931,1 & 2416,0 \\
\hline
\end{tabular}

In the initial period of plant growth, the value of the photosynthetic potential was low. Generally, according to the experiment, in the period from seedlings to autumn tillering, 309-389 thousand $\mathrm{m}^{2} \times$ day / ha. Since the resumption of the spring vegetation and before booting, this indicator was also small - 343-403 thousand $\mathrm{m}^{2} \times$ day/ha. With the development of plants and the extension of the leaf surface, the magnitude of photosynthetic capacity increased. Therefore, in the interphase period "booting flowering", the value of this indicator increased more than twice and amounted to 759-918 thousand $\mathrm{m}^{2} \times$ day/ha. In the next interphase period "flowering - milk-wax ripeness", the value of the photosynthetic potential was also quite high $-913-1093$ thousand $\mathrm{m}^{2} \times$ day / ha.

Therefore, the greatest photosynthetic potential of winter wheat was seen in the period from the moment of "booting" to the grain maturation in an average of 4 years.

The amount of photosynthetic potential also largely depended on the forecrops. So, in the control variant (autumn fallow), the photosynthetic potential for the whole vegetation period was 2325.7 thousand $\mathrm{m}^{2} /$ day / ha. In the variants with the cultivation of beans to grain, this indicator was in the range of 2271.7-2371.9 thousand $\mathrm{m}^{2} \times$ day $/$ ha. The maximum value of this indicator was in the variant with lupine sowing -2371.9 thousand $\mathrm{m}^{2} \times$ day/ha, the minimum-when sowing peas -2308.2 thousand $\mathrm{m}^{2} \times$ day / ha.

Application of legumes as green manure crops boosted the photosynthetic potential to 2449.1-2671.8 thousand $\mathrm{m}^{2} /$ day / ha, which is $6.1-12.6 \%$ more than in the variants where legumes were cultivated to grain. The greatest photosynthetic potential was when using lupine on green manure.

Despite that legumes, as well as complete fallow, leave behind a sufficient amount of nutrients, however, the application of additional mineral fertilizers helps to slightly increase the value of the photosynthetic potential in all variants. In this regard, on complete fallow without mineral fertilizers, this indicator was 2325.7 thousand $\mathrm{m}^{2} \times$ day/ha, and when additional fertilizers were applied at a dose of $\mathrm{N}_{54} \mathrm{P}_{52} \mathrm{~K}_{52}$, the photosynthetic potential increased by 70.5 thousand $\mathrm{m}^{2} \times$ day/ha or by $30 \%$. In the variant with the sowing of lupine on green manure (without fertilization), the photosynthetic potential was 2671.8 thousand $\mathrm{m} 2 /$ day / ha, and with fertilization $3.6 \%$ more.

A special peculiarity of the winter wheat growth is its well-defined plasticity in relation to the growing conditions, which gives it the opportunity to show variability within a wide range. During the growing season, winter wheat goes through certain growth phases. Exposure to external conditions, including agrotechnical ones, may have a significant impact on growth processes, both in the initial growth phases and at the end of the growing season. Therefore, the study of growth indicators in the main growing seasons is essential.

Weather conditions in the study years were not the same, which affected the growth 
rates of winter wheat plants (tabl. 2).

Apart from the weather conditions, the forecrops also affected the growth of the plants. Thus, in 2016, in the phase of booting, the height of the plants in the control version (complete fallow) was $52.1 \mathrm{~cm}$. After peas to grain, the height was $54.3 \mathrm{~cm}$, and after peas to green manure $-55.0 \mathrm{~cm}$. More significant differences in this indicator were after lupine to grain-54.7 cm and to green manure- $56.8 \mathrm{~cm}$. About the same height of plants was after vetch - oat mixture to grain $-55.4 \mathrm{~cm}$ and to green manure-56.1 cm.

Following the bean cultures used to green manure, there is a trend of increasing plant height, relative to the variants where beans were cultivated to grain.

Application of mineral fertilizers had a more significant impact on winter wheat growth. Thus, in the control variant, in the phase of booting, the height of the plants was $52.1 \mathrm{~cm}$, then when applying fertilizers in the dose of $\mathrm{N}_{54} \mathrm{P}_{52} \mathrm{~K}_{52}$. Plants ' height was $61.7 \mathrm{~cm}$, which is $18.4 \%$ more.

Following bean forecrops, cultivated to both grain and green manure, there was an increase in this indicator during mineral fertilizers application. Thus, plants' height in the variants with lupine sowing to green manure was $56.8 \mathrm{~cm}$ without fertilizing, and $66.1 \mathrm{~cm}$ when fertilizing. The number of leaves on the plant within booting was from 6.7 to $7.8 \mathrm{pcs}$ without fertilization and 6.9-7.8 pcs with fertilization. As can be seen, fertilization did not affect this indicator. Following bean forecrops used as green manure, there was an increase in the number of leaves, relative to the control variant.

Table 2. Growth rates of winter wheat plants, according to forecrops and the fertilization (2016-2020)

\begin{tabular}{|c|c|c|c|c|c|c|}
\hline \multirow[b]{2}{*}{ Variants } & \multicolumn{3}{|c|}{ Booting } & \multicolumn{3}{|c|}{ Flowering } \\
\hline & $\begin{array}{l}\text { plants' } \\
\text { height, } \\
\mathrm{cm}\end{array}$ & $\begin{array}{l}\text { number } \\
\text { of leaves, } \\
\text { pcs. }\end{array}$ & $\begin{array}{l}\text { leaf } \\
\text { area, } \\
\mathrm{cm}^{2}\end{array}$ & $\begin{array}{l}\text { plants' } \\
\text { height, } \\
\mathrm{cm}\end{array}$ & $\begin{array}{l}\text { number of } \\
\text { leaves, pcs. }\end{array}$ & leaf area, $\mathrm{cm}^{2}$ \\
\hline \multicolumn{7}{|c|}{ without mineral fertilizers } \\
\hline Complete fallow (control) & 52,1 & 0,7 & 51,9 & 62,9 & 10,2 & 62,1 \\
\hline Peas to grain & 54,3 & 6,9 & 52,1 & 64,7 & 10,8 & 64,7 \\
\hline Peas to green manure & 55,0 & 7,3 & 53,8 & 65,2 & 10,4 & 65,9 \\
\hline Lupin to grain & 54,7 & 7,2 & 53,6 & 64,3 & 10,6 & 65,9 \\
\hline Lupin to green manure & 56,8 & 7,8 & 54,4 & 67,8 & 10,9 & 68,8 \\
\hline Vetch + oats to grain & 55,4 & 6,8 & 51,8 & 65,1 & 10,6 & 63,4 \\
\hline Vetch + oats to green manure & 56,1 & 7,1 & 52,2 & 66,0 & 10,3 & 52,4 \\
\hline $\mathrm{HCP}_{05}$ & 3,01 & 0,59 & 2,97 & 3,04 & 0,61 & 2,17 \\
\hline \multicolumn{7}{|c|}{$\mathrm{N}_{54} \mathrm{P}_{52} \mathrm{~K}_{52}$} \\
\hline Complete fallow (control) & 61,7 & 0,9 & 53,3 & 63,4 & 10,4 & 65,7 \\
\hline Peas to grain & 63,1 & 7,1 & 55,8 & 65,3 & 10,9 & 66,8 \\
\hline Peas to green manure & 69,6 & 7,7 & 56,0 & 65,9 & 10,9 & 68,9 \\
\hline Lupin to grain & 64,2 & 7,4 & 55,9 & 55,6 & 10,8 & 69,7 \\
\hline Lupin to green manure & 66,1 & 7,8 & 58,8 & 68,4 & 11,0 & 72,4 \\
\hline Vetch + oats to grain & 62,9 & 7,8 & 55,6 & 66,0 & 10,9 & 66,3 \\
\hline Vetch + oats to green manure & 63,4 & 7,2 & 55,7 & 66,3 & 10,6 & 65,8 \\
\hline $\mathrm{HCP}_{05}$ & 3,06 & 0,54 & 2,41 & 2,39 & 0,57 & 3,09 \\
\hline
\end{tabular}

Leaf surface area of winter wheat plants depended both on the forecrop and on 
fertilization. In the case of the studied forecrops, the largest leaf area was found in the variant with lupine sowing to green manure, which was $54.4 \mathrm{~cm}^{2}$, which is $4.8 \%$ more than in the control variant. In the other variants, there are less significant differences relative to the control one.

Mineral fertilizers have had a positive effect on the leaf surface area of winter wheat plants. As previously mentioned, the leaves area in the variant with the sowing of lupine to green manure (without fertilizing) was $54.4 \mathrm{~cm} 2$. When applying mineral fertilizers, the value of this indicator was $58.8 \mathrm{~cm} 2$, which is $8.1 \%$ more. A similar trend is seen in other indicators.

By the flowering phase, winter wheat plants reach a maximum in their development. In the future, there is a decay of growth, the death of part of the leaves, etc. Thus, it is in this phase it is important to know the growth characteristics.

Plants ' height in the indicated growth phase was $64.3-67.8 \mathrm{~cm}$ in the variants with bean forecrops, compared to $62.9 \mathrm{~cm}$ in the control variant. Moreover, in all variants, with the exception of lupine, the height of winter wheat plants was almost the same both in variants grown to grain and grown to green manure. In the variant with the cultivation of lupine to green manure, plants' height was $67.8 \mathrm{~cm}$, and to grain $-64.3 \mathrm{~cm}$.

Fertilization did not affect the height of winter wheat plants. In the control version, the height of the plants without fertilization was $62.9 \mathrm{~cm}$, with fertilization $-63.4 \mathrm{~cm}$. The differences were within the range of the experiment error. In the remaining variants, a similar pattern can be observed.

The number of leaves in the variants without mineral fertilizers was $10.2-10.9 \mathrm{pcs}$. The largest number was in the variant with the cultivation of lupine to the green manure. Application of fertilizers in a dose of $\mathrm{N}_{54} \mathrm{P}_{52} \mathrm{~K}_{52}$ practically had no impact on this indicator, which was 10.4-11.0 pcs according to the experiment.

At the time of flowering, the leaf surface area of winter wheat plants in the variants where beans were cultivated as forecrops ranged from $62.4 \mathrm{~cm} 2$ to $68.8 \mathrm{~cm} 2$, compared to $62.1 \mathrm{~cm} 2$ in the control. In the variants where vetch-oat mixture was cultivated, the leaf area was at the level of the control variant. After lupine, which was cultivated for both grain and green manure, the area of winter wheat leaves was the largest.

Application of mineral fertilizers positively affected this indicator, as well as within booting. In the control variant, the leaf area increased by $5.8 \%$ compared to the same variant without mineral fertilizers. In the other variants, a similar trend is observed.

As you know, yield is an essential indicator allowing to evaluate the developed agrotechnological measures.

The harvest in study years was not the same and depended on weather conditions. Nevertheless, regardless of the weather changes, the winter wheat crop was more dependent on its forecrops and fertilizer application.

Thus, in 2016, the yield in the control variant (without fertilization) was $3.14 \mathrm{t} /$ ha. Meanwhile, the crop was on the same level as complete fallow crop in the variants where bean to grain were cultivated as forecrops-3.16-3.29 $\mathrm{t} / \mathrm{ha}$.

In the variants where beans were cultivated to green manure, the yield was slightly higher and amounted to 3.24-3.57 $\mathrm{t} /$ ha depending on the bean cultures types. The highest yield of winter wheat was after lupine to green manure $-3.57 \mathrm{t} / \mathrm{ha}$.

Application of mineral fertilizers had the greatest impact on the yield of winter wheat. In the complete fallow (control), the yield increased by $23.2 \%$, in the variants with beans grown to grain by $21.5-27.9 \%$, and in the variants with green manure by $17.6-22.9 \%$.

In 2017, green manure provided an increase in yield relative to the control variant (without mineral fertilizers) by 1.1-5.4\%, while the variants with the cultivation of bean were at the level of the control variant. 
Application of mineral fertilizers has increased the yield of winter wheat in all variants by $7.5-13.5 \%$.

The highest yield of winter wheat was received in 2018, which varied according to experience from $4.06 \mathrm{t} /$ ha to $4.79 \mathrm{t} / \mathrm{ha}$, depending on the version. As in previous years, the yield after bean cultures grown to grain was at the level of complete fallow of 3.74-3.87 $\mathrm{t} /$ ha against $3.69 \mathrm{t} / \mathrm{ha}$ in the control version.

After the green manure fallows, the yield in the variants without mineral fertilizers was $3.77-3.88 \mathrm{t} / \mathrm{ha}$, which slightly outperformed the previous versions.

Application of mineral fertilizers in a dose of N54P52K52 increased the yield in all variants by $10.6-11.7 \%$. The highest yield was received in the variant after lupine to green manure $-4.79 \mathrm{t} /$ ha.

A similar trend in the yield of winter wheat was observed in 2019. It also produced the highest yield after lupine to green manure on the background of mineral fertilizers $-4.46 \mathrm{t}$ / ha, which exceeded the control by $7.8 \%$.

The average yield of winter wheat after growing bean cultures to grain was $3.68-3.78 \mathrm{t} /$ ha (without fertilizers), which was practically at the level of complete fallow-3.67 t/ ha. On the background of mineral fertilizers, the winter wheat yield in similar variants was 4.22 $4.43 \mathrm{t} / \mathrm{ha}$, which exceeded the control by $0.9-4.7 \%$.

After green manure crops, the winter wheat yield slightly outperformed the crop in the variants where bean cultures were cultivated to grain, both without fertilization and with fertilizers applied.

Application of mineral fertilizers promoted obtaining of the bigger increase in a crop, unlike the forecrop. With the application of mineral fertilizers, the yield increased by 11 $12 \%$ in similar variants.

In all the years of the study, the largest increase in the winter wheat crop was received after lupine to green manure with the application of mineral fertilizers $-4.56 \mathrm{t} / \mathrm{ha}$.

\section{Conclusion}

On the basis of the above, we can conclude the following:

1. Beans planted to green manure as a forecrop to winter wheat have a noticeable effect on the process of forming the assimilation mechanism of the plants. The maximum leaf surface area in the flowering phase was 42.6-49.7 thousand $\mathrm{m} 2$ / ha.

2. Application of bean cultures as green manure crops promotes the growth of the photosynthetic potential of winter wheat up to 2449.1-2671.8 thousand $\mathrm{m} 2$ /day / ha, which is $6.1-12.6 \%$ more than in the variants where bean were cultivated to grain.

3. Application of beans as forecrops contributes to increase the yield of winter wheat. The use of beans as forecrops helps to intensify the yield of winter wheat. The best forecrop for winter wheat, which ensures the highest yield, is lupine to green manure.

\section{References}

1. S.I. Barshatskaya, Politemat. Set. Elektr. Nauch. Zhurn. Kub GAU, 120, 1305 (2016)

2. A.M. Berezin, Green fertilizers in Central Siberia (Krasnoyarsk: Izdatelstvo Krasnoyarskogo GAU, 395 2002)

3. G.P. Gamzikov, Dostizh. Nauk. i tekh. APK, 3, 9 (2012)

4. A, Kozhukhov, A. Gurin, S. Rezvyakova, E3S Web of Conferences. International Conference on Efficient Production and Processing, ICEPP 2020, 01103, 9, 37 (2015)

5. V.M. Perederieva, Sovrem. probl. nauk. i obrazov., 5, 3 (2012) 
6. N.N. Tikhonov, Mol. Uch, 192 (2016)

7. V.I. Trusov, Vest. Michur. GAU, 2, 6(2019)

8. G.R. Dorozhko, Res. J. of Pharm. Biol. and Chem. Scien., 8(6), 819(2017)

9. K.M. Oliinyk, Pl. Var. Stud. and Prot., 4 (33), 45(2016)

10. M. Lozinskyi, Arpob., 1 (124), 22 (2016)

11. G.F. Nikitienko, Experiments in farming (Moscow: Rosselkhozizdat, 190, 1982) 